\title{
EL ESTADO AUTONÓMICO Y LA COVID-19
}

\author{
José Tudela Aranda \\ Letrado de las Cortes de Aragón. \\ Secretario General de la Fundación Manuel Giménez Abad
}

Cómo citar este artículo / Citation: Tudela Aranda, J. (2021). El Estado Autonómico y la covid-19. Tudela Aranda, J. (coord.)

Estado Autonómico y covid-19, Colección Obras colectivas, Fundación Manuel Giménez Abad, Zaragoza. DOI: https://doi.org/10.47919/FMGA.OC21.0211

SUMARIO: I. PRESENTACIÓN A MODO DE EXPLICACIÓN - II. VALORACIÓN GLOBAL DE LA RESPUESTA DEL ESTADO AUTONÓMICO A LAS EXIGENCIAS DE LA CRISIS - III. APROXIMACIÓN A LOS PROBLEMAS PLANTEADOS POR LOS DOS MODELOS DE ESTADO DE ALARMA - IV. LÍMITES DE LA CAPACIDAD DE LAS COMUNIDADES PARA INCIDIR SOBRE DERECHOS - V. LECTURAS PARA EL FUTURO

\section{PRESENTACIÓN A MODO DE EXPLICACIÓN}

La crisis provocada por la pandemia ha vuelto a poner al Estado autonómico en el foco del debate público. En realidad, dado que, por una u otra razón, nunca ha estado fuera, lo singular es que se ha fijado la atención en cuestiones hasta ahora marginales. Las reflexiones que se han realizado durante estos meses han estado dominadas por análisis de eficacia y eficiencia, aunque, inevitablemente, no haya faltado alguna disquisición sobre la relación entre gestión de la excepcionalidad y el autogobierno. Es importante. $Y$ hay que agradecerlo porque, tradicionalmente, la funcionalidad del Estado no ha sido una cuestión a la que se haya prestado gran atención, siendo subordinada casi de forma generalizada a la dialéctica descentralización/centralización. Después de lo sucedido, la reflexión sobre este punto será imprescindible. Lo reclaman 
los ciudadanos, pero, aún más relevante, lo exige el futuro del Estado y la propia supervivencia de los valores que representa el Estado autonómico. Al respecto, la epidemia permite extraer lecciones no desdeñables. Sin exagerar, entiendo que debe servir para renovar el pensamiento sobre este tema. Debe ser la catapulta que sirva para modernizar y renovar nuestras reflexiones. Porque la dialéctica centralización/descentralización y las cuestiones identitarias, por importantes que sean, son antiguas. Antiguas en el sentido de que, desde los planteamientos más tradicionales, no es posible responder a los desafíos del nuevo modelo social. Encontrar las respuestas adecuadas a los retos que plantea debe considerarse el gran objetivo contemporáneo de la política. Por supuesto, esos desafíos también tienen una perspectiva territorial. Un análisis correcto, un análisis que nos aproxime a las soluciones, debe realizarse teniendo en cuenta los cambios sociales, económicos y tecnológicos y teniendo a la eficacia y la funcionalidad como guías en la respuesta.

Una segunda cuestión que sirve como premisa es que una visión superficial de lo sucedido en Estados centralizados y en otros federales homologables al nuestro, muestra que el factor que ha condicionado el acierto o el fracaso en la gestión no ha sido el modelo territorial ${ }^{1}$. Es fácil predecir que se alzarán voces responsabilizando al Estado autonómico de algunos de los males de estos meses y pidiendo actuar en consecuencia, es decir, demandando una mayor centralización de las políticas públicas. Desde el principio hay que advertir sobre este extremo. Sin duda, puede haber problemas ligados al modelo territorial, y, más concretamente, a algunas de las dinámicas adquiridas en el desarrollo constitucional del modelo. Pero todos, o casi todos, esos problemas hubiesen podido ser resueltos con una gestión virtuosa por parte de los diferentes responsables políticos.

En tercer lugar, cabe hacer una reflexión que transciende lo sucedido durante estos meses, aunque en los mismos se haya manifestado con una inquietante perseverancia. La autonomía nos gusta cuando sirve para amparar aquellas decisiones que consideramos correctas. Las mismas formaciones políticas que reclaman la máxima autonomía para este o aquel territorio, se escandalizan e intentan limitar las decisiones adoptadas por otro, normalmente gobernado por

\footnotetext{
1 Al respecto, Rupak Chattopadhyay, Felix Knüpling (ed.), Dealing with the COVID crisis in Federal and Devolved Countries, Foro de Federaciones, Palgrave, 2020.
} 
una fuerza política diferente. Hay que aprenderlo de una vez por todas. Autonomía es respeto a la diversidad y el único límite a esa diversidad es la Constitución y su desarrollo por el bloque de constitucionalidad, por más que se pueda renegar de determinadas opciones.

Estas palabras introductorias deben finalizar con la cautela que implica escribir sobre un proceso aún vivo. Se pueden obtener ya importantes conclusiones sobre las afecciones que para el Estado autonómico ha tenido la covid-19 e, incluso, aventurar alguna línea de futuro. Pero estas palabras se escriben en marzo de 2021, cuando aún quedan largos meses de convivencia con el virus. Incluso es pronto para reflexionar por escrito sobre lo sucedido. Inevitablemente, hay un mucho de provisionalidad en ello. Con todo, es preciso comenzar a madurar ideas que deberán servir de base para la imprescindible evaluación crítica que ha de venir.

\section{VALORACIÓN GLOBAL DE LA RESPUESTA DEL ESTADO AUTONÓMICO A LAS EXIGENCIAS DE LA CRISIS}

La crisis sanitaria causada por la covid-19 ha generado distintos desafíos al Estado y, entre ellos, no son los menos relevantes los planteados al modelo de descentralización política. Antes de cualquier consideración, hay que recordar que ha tenido lugar en un momento de particular debilidad de la forma de organización territorial del poder que representa el Estado autonómico. Por una parte, con el desafío secesionista aún vivo y, lo más transcendente en esta ocasión, con la nula voluntad de colaboración por parte de los dirigentes de una de las más importantes Comunidades Autónomas. Por otra, con todos los problemas de carácter más "técnico" (relaciones intergubernamentales; financiación; delimitación de competencias...) diagnosticados hasta el cansancio, pero detenidos en el tiempo y, por ende, objeto de paulatina erosión ${ }^{2}$. En estas condiciones, la pandemia ha provocado una situación no sólo excepcional sino inédita $y$, en buena medida, imprevisible. El eje de la crisis revertía sobre una competencia autonómica, pero desde la declaración oficial de la emergencia (Real Decreto 463/2000) todas las miradas de los

\footnotetext{
2 Los diversos avatares y, en última instancia, el fracaso del último intento de abordar de forma general la reforma de la organización territorial (La Comisión para la Evaluación y Modernización del Estado Autonómico creada en el Congreso de los Diputados), sintetiza y simboliza el destino final de cuántas propuestas de reforma se han elaborado.
} 
ciudadanos estaban dirigidas hacia el Gobierno de la Nación. Y no sólo por una reacción instintiva, natural en una situación de estas características. También porque así debía ser ya que el citado Decreto alteraba radicalmente el estatus quo, concentrando en el Estado de forma exclusiva la gestión de la crisis. El Ministerio de Sanidad, hasta ahora reconocido por su inanidad, cuasi vacío de competencias y personal, pasaba a ser responsable de una gestión que pronto se mostró como ingente. Este modelo se mantuvo hasta el final de la declaración de alarma, si bien con alguna modulación según transcurría el tiempo. La aprobación del segundo estado de alarma (Real Decreto 926/2020, de 25 de octubre) supuso un cambio radical en la forma de organizar la gestión de la pandemia desde la perspectiva territorial. El mando único se disgregó en 17 mientras el Ministerio regresaba a su habitual posición de marginalidad, al menos sobre la letra del Real Decreto. En otro apartado, explicaré lo que a mi juicio significa la posible convivencia de dos modelos tan radicalmente diferentes. Pero he de adelantar que el hecho de que hayan podido convivir de forma sucesiva denota la existencia de un problema estructural en el diseño del modelo territorial.

¿Cómo se puede valorar la respuesta del Estado autonómico a la crisis sanitaria? La respuesta es complicada. De entrada, lo único sencillo (y necesario), es descartar los trazos gruesos. Es decir, tanto el hacer recaer sobre el modelo descentralizado una presunta respuesta global ineficiente como quedarse en la complacencia o en un mero reparto de responsabilidades políticas en función de qué lado de la mesa nos sentemos. La mayor o menor descentralización del poder, como se dijo, no ha condicionado en abstracto la respuesta a la pandemia. Ni siquiera es sencillo determinar cuál puede ser la responsabilidad de cada sistema político en concreto cuando del virus se desconoce mucho. Así, es preciso destacar tanto la provisionalidad de cualquier análisis como advertir sobre el riesgo de error. Con todo, se puede y se debe realizar un mínimo ejercicio valorativo, siempre teniendo presente que no se enjuicia el buen o mal hacer de los distintos responsables sino la respuesta de las dinámicas institucionales ante una crisis excepcional.

Desde las premisas anteriores, mi juicio sobre el desenvolvimiento de nuestro modelo territorial es positivo, moderadamente positivo, como, aún con demasiada brevedad, intentaré justificar. La premisa de esta afirmación es que, a pesar de todas las dificultades, incluyendo el en demasiadas ocasiones no 
muy responsable comportamiento de los dirigentes políticos, el sistema ha permitido, al menos, un mínimo razonable de funcionalidad. Dicho de otra manera, ha mostrado suficientes recursos como para ofrecer respuestas incluso a premisas que no pueden describirse como virtuosas. Evidentemente, ello no significa que todo haya funcionado bien, que no haya habido, incluso, importantes problemas. Por una parte, era inevitable dado lo extraordinario y novedoso de la situación. Por otro, ni el modelo se encontraba en plenitud ni sus actores facilitaban el mejor desenvolvimiento.

La primera virtud que ha demostrado el modelo autonómico durante estos meses, es la flexibilidad. Inmediatamente debe decirse que sólo ha ratificado una cualidad normalmente desdeñada. La capacidad de adaptación a las más variadas circunstancias se ha vuelto a demostrar tanto por su capacidad de mantenerse esencialmente vigente en una circunstancia excepcional como por su natural ambivalencia, al ser capaz de cobijar incluso modelos radicalmente diferentes. En numerosas ocasiones, se critica el Estado autonómico por su indeterminación, por ser un modelo abierto, incluso por las contradicciones en su diseño. Gran parte de esas críticas responden simplemente a una descripción objetiva del modelo. No se trata de un diseño cerrado ni de un modelo extraído de ningún aula académica. $Y$ sin duda, ello ocasiona problemas. Pero también se ha demostrado sobradamente que le dota de gran flexibilidad. De una flexibilidad que, además, se adapta bien a la idiosincrasia política y territorial de este País.

Junto a lo anterior, destacaría el nivel de eficacia general logrado. Es cierto que la valoración global de la gestión de la crisis en España necesita de un ejercicio de autocrítica cuando las cifras derivadas de la misma, tanto en lo sanitario como en lo económico, son particularmente negativas. Pero no parece que ese resultado se pueda asociar mayoritariamente a la descentralización política y, ni siquiera, con la gestión por las autoridades autonómicas. Los principales problemas asociados al modelo territorial tuvieron lugar en las primeras semanas de la pandemia cuando la sensación (y realidad) de que cada Comunidad intentaba alcanzar los medios necesarios para contener al virus no sólo provocó una negativa imagen del Estado autonómico sino daños adicionales al resultado de la gestión. Y, además de cuánto de inevitable había en ese momento, en todo caso, no se trataba de responsabilidad ni de las autoridades autonómicas ni del diseño territorial. El juicio sobre la eficacia no 
debe anudarse a la mejor o peor gestión de los responsables autonómicos. Es un juicio que deriva de la apreciación de si el Estado autonómico ha dotado a los distintos poderes de las herramientas necesarias para responder a la crisis. Y creo que la respuesta es afirmativa. No sólo no ha habido problemas de gestión indisolublemente ligados al modelo territorial, sino que en todo caso se han encontrado en el mismo los instrumentos precisos para hacer frente a la crisis en el modo en el que en cada momento se ha querido por las diferentes autoridades.

Finalmente, mi valoración es positiva por dos razones añadidas. En primer lugar, por la garantía de la diversidad que implica el Estado autonómico y, simultáneamente, por el valor irrenunciable de esa diversidad. Diversidad que no sólo se ha traducido en la capacidad de cada territorio de adaptar la política a sus específicas circunstancias, sino que también ha servido de laboratorio para propiciar nuevas herramientas contra la epidemia. En segundo lugar, por el valor constitucional del control político. La epidemia nos ha recordado la intrínseca relación de la descentralización con el control tanto vertical, entre las diferentes Comunidades y el Estado, como horizontal, al diversificar el control parlamentario en dieciocho escenarios. Repito que este juicio positivo es necesariamente independiente de la valoración del uso que se haya hecho de ello.

\section{APROXIMACIÓN A LOS PROBLEMAS PLANTEADOS POR LOS DOS MODELOS DE ESTADO DE ALARMA}

Como es sabido, los dos Decretos que declararon el estado de alarma ${ }^{3}$, plantean dos modelos de gestión territorial que no pueden calificarse sólo como diferentes. Más bien, son radicalmente distintos. Por una parte, el Real Decreto 463/2020, de 14 de marzo, establecía un modelo de concentración de la gestión en el Estado que recibió la denominación de mando único. Ese mando era el del Presidente del Gobierno que concentraba las decisiones en su persona con el apoyo de un reducido número de ministros. Más allá de la letra de la norma, durante su vigencia quiso visibilizar ese mando único con

\footnotetext{
3 Hay un tercer Real Decreto declarando el estado de alarma, pero limitado exclusivamente a algunos municipios de la Comunidad Autónoma de Madrid (Real Decreto 900/2020, de 9 de octubre, por el que se declara el estado de alarma para responder ante situaciones de especial riesgo por transmisión no controlada de infecciones causadas por el SARS-CoV-2.
} 
comparecencias semanales para explicar la evolución de la pandemia. Por el contrario, el Real Decreto 926/2020, de 25 de octubre, por el que se aprueba el segundo estado de alarma difiere radicalmente de esos presupuestos. La autoridad competente pasa a ser, por delegación del Presidente del Gobierno, los Presidentes de las Comunidades Autónomas. De alguna manera, desde su entrada en vigor, el Estado desaparece de la gestión de la pandemia. Un marco mínimo se estableció en el texto del Real Decreto y subordinados al mismo, los responsables de la gestión pasan a ser los Presidentes de las Comunidades Autónomas. Así las cosas, se plantean diferentes cuestiones. En primer lugar, un análisis jurídico de cada uno de estos dos modelos. En segundo lugar, es forzoso preguntarse por su coexistencia. En líneas anteriores he subrayado como la flexibilidad se ha vuelto a mostrar como una relevante cualidad del modelo autonómico. Pero ante una disparidad tan radical y en una cuestión de gran transcendencia, es inevitable preguntarse tanto por la oportunidad de la disparidad como, incluso, por la adecuación de su convivencia con el modelo territorial vigente en nuestro País. Volveré a ello brevemente, tras aludir a las implicaciones de los dos modelos citados.

En una primera aproximación, es posible coincidir en que, una vez declarado el estado de alarma en relación con una crisis sanitaria grave y generalizada a todo el territorio, era razonable la concentración de la decisión última en el Estado. De hecho, la mera aprobación de la alarma lleva implícita una concentración de poder con las posibles medidas recogidas en el texto que sustenta la declaración. Desde esta premisa, también parece evidente que las características de nuestro modelo territorial obligan en cualquier caso a flexibilizar ese mando único. No sólo por razones jurídicas. También, y sobre todo, por evidentes razones operativas. Gran parte de las competencias en materia de sanidad, incluyendo todas las de gestión, corresponden a las Comunidades Autónomas y la declaración del estado de alarma no altera ni puede hacerlo en su núcleo ${ }^{4}$. Por más que se concentrasen los poderes de decisión en el Estado, la gestión cotidiana de los servicios sanitarios, correspondía a las Comunidades Autónomas. Así, si bien el establecimiento del mando único parece compatible con el derecho de excepción vigente y en consecuencia no objetable desde el reparto de competencias, no parece, por el

\footnotetext{
4 Vid P. Biglino Campos (Coord), Los efectos horizontales de la COVID-19 sobre el sistema constitucional: estudios sobre la primera oleada, Fundación Manuel Giménez Abad, Zaragoza, 2021.
} 
contrario, que su aplicación sin modulación pueda merecer un juicio positivo. El reparto de competencias vigentes exigía diseñar un protocolo de colaboración en el que el rol de las Comunidades Autónomas fuese acorde con sus competencias en la materia. Un desempeño que sería perfectamente compatible con la concentración de la decisión en el Gobierno del Estado, tal y como establecía el Decreto del estado de alarma. Sin embargo, las Comunidades Autónomas apenas desempeñaron un papel de oyentes de las decisiones tomadas en las sucesivas conferencias de Presidentes celebradas de forma virtual. Las decisiones se tomaban previamente y se comunicaban en estas reuniones. Con el transcurso de las semanas, la situación se moduló ligeramente, básicamente por las presiones de las Comunidades Vasca y Catalana, y por las exigencias correspondientes de los partidos nacionalistas en el Congreso para autorizar las sucesivas prórrogas del estado de alarma.

Muchas más dudas jurídicas, y las mismas de oportunidad, plantea el modelo adoptado en la segunda declaración del estado de alarma, es decir la delegación del ejercicio de las competencias antes concentradas en el mando único en los Presidentes de las Comunidades Autónomas (artículo 2). Una delegación que, de acuerdo con lo dispuesto en el artículo 2.3, habilita a las autoridades delegadas a dictar las órdenes, resoluciones y disposiciones para la aplicación de lo dispuesto en los artículos 5 a 11, núcleo del Real Decreto. El artículo 12 aclara que cada administración conservará las competencias que le asigna la legislación vigente. Sólo en el artículo 13 se realiza una referencia a la "necesaria coordinación" y cabe calificarla, cuando menos, de ligera. De acuerdo con la misma, el Consejo Interterritorial del Sistema Nacional de Salud podrá adoptar los acuerdos que procedan. No parece que esta disposición añada ninguna competencia particular a este organismo.

Como se indicó, este modelo plantea dudas jurídicas relevantes. Al respecto, en una y otra posición ha habido ya relevantes pronunciamientos ${ }^{5}$. Por mi parte, sólo quiero subrayar las dos cuestiones que estimo más cuestionables. Por un lado, la aparente contradicción entre los presupuestos de hecho que determinan la alarma y la inhibición del Gobierno del Estado en relación con su gestión. Por otra, el amplio margen que se otorga a las Comunidades Autónomas para restringir, sino directamente, suspender derechos. Como en

${ }^{5}$ Con especial contundencia y claridad expresó su crítica el profesor Tajadura (Estado de alarma y seguridad jurídica, El País, 27 de octubre de 2020). 
otros aspectos relacionados con esta crisis, creo que, en ocasiones, y más allá de la literalidad de las normas, se minusvaloran criterios interpretativos esenciales como pueden ser su sentido teleológico, la interpretación restrictiva que merece toda situación excepcional o el principio de proporcionalidad, por citar sólo alguno de los más relevantes ${ }^{6}$. Como la relación con los derechos la examinaré en el siguiente apartado, me limito a plantear alguna duda general sobre la figura de la delegación.

Un estado de alarma, como indicó el Tribunal Constitucional, implica la emergencia de un derecho de excepción al amparo del cual el poder ejecutivo asume poderes excepcionales. Por definición, ese poder sólo puede ser el del Gobierno del Estado, único competente para declarar la alarma. Así, parece complicado encajar la figura de la delegación en este esquema. Más si se proyecta sobre la delegación cualesquiera de los principios citados u otros similares. ¿La excepcionalidad que refleja el propio texto del Real Decreto es compatible con su expansión a diecisiete ejecutivos? En todo caso, parece que los poderes que se pudieran atribuir a las Comunidades Autónomas debieran haber sido delimitados con mucha mayor precisión, evitando la amplitud de la delegación que se comenta. Una cuestión adicional que se plantea es la del control de esa delegación. Una sola pregunta es suficiente para resumir dudas: de acuerdo con la estructura de la delegación ¿Hay que entender que el delegante es el responsable último de todos los actos ejecutados en virtud de la misma?

Desde el Gobierno se ha caracterizado este modelo como cogobernanza. Al margen de las dudas que suscita semejante voz, creo que la filosofía, como en el caso del primer estado de alarma, se aleja de cualquier modelo colaborativo. Al revés, parece que se ha huido de la complejidad para refugiarse en modelos simples de gestión unilateral. No puede denominarse cogobernanza a la mera referencia a las reuniones del Consejo Interterritorial de Salud, única previsión que se acerca a la colaboración. Finalmente, es inevitable acabar recordando la premisa de partida. El artículo 149.1.16 atribuye al Estado la coordinación general de la sanidad. Parece difícil de objetar que en una situación de alarma esa competencia de coordinación se intensifica. $Y$ durante los meses de

${ }^{6}$ Vid. C. Garrido, Naturaleza jurídica y control jurisdiccional de las decisiones constitucionales de excepción, Revista Española de Derecho Constitucional, ํo 110, 2017, pp. 47-73. 
vigencia de esta segunda alarma, esa competencia se ha cuasi diluido por completo.

Más allá de la valoración de cada modelo en singular, es preciso reflexionar sobre la convivencia de dos planteamientos tan radicalmente opuestos. Es una pregunta necesaria tanto desde el análisis jurídico como desde el de oportunidad. Es cierto que entre el tiempo de la declaración del primer estado de alarma y el correspondiente al segundo, existen diferencias sustantivas. El tiempo transcurrido entre uno y otro nos ha dotado de unos conocimientos y una experiencia que influyen en las decisiones de los gobernantes. Pero ¿ésa diferencia es suficiente para explicar un cambio tan radical del modelo de gestión territorial? Como no ha habido ninguna explicación por parte de quién ha decidido, cabe entender que sí, que la experiencia acumulada ha sido la razón para entender que la epidemia se combatía mejor con el fraccionamiento absoluto de su gestión. Al margen de las dudas de oportunidad que se puedan tener al respecto, cabe preguntarse sobre la viabilidad de esta alternativa de modelos en nuestra organización territorial. En mi opinión, se trata de una disyuntiva demasiado radical. Tanto que aceptarla implica una visión cuasi desconstitucionalizada del modelo. $Y$ del bloque de constitucionalidad en materia sanitaria y en otras competencias convergentes se deduce un marco jurídico en el que difícilmente pueden encajar simultáneamente los dos modelos y, en particular, el segundo.

\section{LÍMITES DE LA CAPACIDAD DE LAS COMUNIDADES PARA INCIDIR SOBRE DERECHOS}

Una de las cuestiones más complejas a las que se ha enfrentado la pandemia ha sido a la relación entre las Comunidades Autónomas y los derechos y libertades. Es este un tema recurrente, nunca del todo resuelto ${ }^{7}$. Pero hasta ahora, los problemas se habían suscitado alrededor de la capacidad de las Comunidades Autónomas para desarrollar en positivo determinados derechos. No había suscitado debate su margen para limitarlos o, incluso, suspenderlos. El protagonismo que han tenido las Comunidades en la gestión de la epidemia

\footnotetext{
7 Un debate primero construido alrededor de la interpretación de la cláusula del artículo 149.1.1ำ de la Constitución y posteriormente alrededor de la inclusión en los Estatutos de Autonomía de segunda generación de declaraciones de derechos y libertades.
} 
ha planteado este tema incluso de forma violenta. Incidentalmente, hay que decir que tampoco el Estado se ha visto ajeno a la polémica suscitada alrededor de medidas adoptadas que afectaban a los derechos y libertades. De hecho, la primera de las relevantes polémicas jurídicas suscitada durante estos meses tuvo como objeto la disyuntiva suspensión/limitación de derechos aneja a la declaración del primer estado de alarma ${ }^{8}$.

En relación con las Comunidades Autónomas, es preciso distinguir entre las tres etapas que hasta hoy se pueden diferenciar en la gestión de la epidemia. La primera de ellas se corresponde con el primer estado de alarma. Como se ha analizado, durante la misma, el Estado concentró la decisión y, en consecuencia, las Comunidades Autónomas fueron ajenas a las muy severas restricciones sufridas por numerosos derechos y libertades. Estas fueron comunes y generales para todo el territorio nacional y la acción de las Comunidades se concentró en la gestión cotidiana de los servicios sanitarios y sociales. Una situación que fue comúnmente aceptada y, me atrevo a decir, entendida por la mayoría de los ciudadanos como la que correspondía a la situación que se vivía. Algo que sólo se modificó cuando la epidemia comenzó a declinar y las Comunidades reivindicaron disponer de cierto margen de actuación para adaptar las medidas a las circunstancias específicas (o para ejercer el autogobierno, que fue la bandera más reivindicada).

Así, se llegó a la segunda etapa, la denominada desescalada, a la postre una mera transición entre la primera y la segunda alarma, entre la primera y segunda o tercera ola de la epidemia, según se quiera ver. Se trata de la etapa más confusa en términos jurídicos y aquella que concentra el núcleo del debate en este tema, ya que, en la tercera etapa, vigencia del segundo estado de alarma, los posibles conflictos que se planteen se encontrarán condicionados por la ya analizada premisa de la delegación de competencias en los Presidentes autonómicos. En principio, se trataba de un tiempo de cuasi normalidad. El virus, en palabras del Presidente del Gobierno, había sido vencido y era preciso recobrar la normalidad, aunque fuese modulada. La finalización del estado de alarma y la llegada del verano fueron para muchos

\footnotetext{
8 Defendiendo la inadecuación del estado de alarma con las medidas adoptadas, M. Aragón Reyes, Epílogo en Los efectos horizontales de la COVID-19 sobre el sistema constitucional: estudios sobre la primera oleada, ob. cit. En un sentido contrario, Cruz Villalón, P., La Constitución bajo el estado de alarma, El País, 17 de abril de 2020, disponible en: https://elpais.com/elpais/2020/04/16/opinion/1587025782_733659.html
} 
ciudadanos las señales de que aquello era verdad. Pronto se comprobó que la realidad distaba de ser tan amable. El virus seguía presente y aprovechaba cualquier descuido para recordarlo. En todo caso, había una diferencia notable en relación con lo sucedido en marzo. Si en esa fecha la epidemia se encontraba activa en todo el territorio nacional, aunque, lógicamente, con intensidades varias, en esta etapa de transición, su expansión territorial se caracteriza por ser voluble. Si bien finalmente alcanzó a casi todas las Comunidades, lo hizo en tiempos diferentes y con intensidad diversa. Un dato importante para el tema que se analiza porque ello fue causa de que por las Comunidades se fuese respondiendo en virtud de la coyuntura. En algunos casos, la epidemia volvió a hacerse presente con intensidad y fue preciso adoptar medidas con incidencia sobre los derechos y libertades. Muchas optaron por aprobar un decreto u orden de habilitación general para adoptar esas medidas ${ }^{9}$. Como señalé, estas actuaciones suscitan dudas. Frente a algunas de ellas, se plantearon recursos y los tribunales respondieron en una forma no siempre coherente, sin olvidar las diferencias que plantean cada caso. Dadas las características de estas páginas, obvio el análisis de las sentencias y con él, la estricta delimitación de los límites de las Comunidades Autónomas para incidir sobre los derechos, para centrarme en una serie de reflexiones generales.

Dos consideraciones deben tener carácter previo. Por una parte, el hecho de que el resurgir de la epidemia no podía considerarse un hecho inesperado. Más bien, al contrario. En este sentido, sorprende la ausencia de planes de contingencia y protocolos previos y, especialmente, por lo que nos interesa, la ausencia de un marco normativo que permitiese, en su caso, actuar en consecuencia y con seguridad jurídica. Otros Estados habían introducido reformas legislativas que facilitaban la respuesta a la crisis ${ }^{10}$. Por otra parte, la disyuntiva a la que se encontraron abocados los responsables autonómicos era siniestra. Con lo que parecían severas limitaciones normativas, debían hacer frente a brotes de la enfermedad en ocasiones muy severos.

\footnotetext{
9 Un ejemplo de estas disposiciones y de los problemas jurídicos que suscitan es el Acuerdo del Consejo de Gobierno de 7 de septiembre de 2020, por el que se habilita a la consejera de Salud y Consumo para la adopción de medidas temporales y excepcionales para la contención de la COVID 19 en determinadas áreas geográficas (BOIB no 154, 7 de septiembre de 2020).

10 Vid, M. Köelling, Las instituciones democráticas y los derechos fundamentales en caso de crisis en Alemania en Vid P. Biglino Campos (Coord), Los efectos horizontales de la Covid-19 sobre el sistema constitucional: estudios sobre la primera oleada, ob. cit.
} 
Una y otra Comunidad, antes o después, adoptaron durante estos meses medidas que incidían en un número amplio de derechos. Derechos y libertades como circulación, culto, manifestación, reunión, libertad de empresa... se vieron seriamente afectados por decisiones que en algunos casos se amparaban en la orden de un Consejero y en la mayoría, en una disposición reglamentaria. Así, dos eran los temas controvertidos. Por un lado, la mera capacidad de las Comunidades Autónomas para restringir derechos. Por otro, el rango de las disposiciones al amparo de las cuales se adoptaron estas decisiones. Los recursos planteados contra varias de esas medidas no ayudaron a aclarar de manera contundente el tema. $\mathrm{Y}$ las Comunidades llegaron a buscar en la fórmula del Decreto-Ley, al menos un amparo normativo suficiente ${ }^{11}$, incorporando de esta manera al debate alguna cuestión adicional.

La situación era compleja en lo material y de difícil resolución jurídica de una manera ortodoxa. En puridad, es cuestionable que una norma autonómica pueda restringir severamente derechos. $Y$ creo que no admite demasiadas dudas que no puede hacerse por decreto u orden. En paralelo, un derecho de particular relevancia, derecho a la vida, se encontraba en riesgo. Mi opinión es que, ante esta situación, y dada la ausencia de legislación estatal de cobertura, lo más razonable y menos inconveniente hubiese sido la aprobación por los Parlamentos autonómicos de una ley de emergencia que dotase de amparo legal a las decisiones del ejecutivo y de seguridad jurídica a los ciudadanos. En un Parlamento autonómico esa ley se podía haber aprobado en menos de dos semanas y su contenido se podría haber adaptado a las necesidades de cada territorio. $Y$ debería haber sido aprobada en paralelo al final del estado de alarma. Desde luego, se puede alegar que ello no resuelve la duda de la disponibilidad de las Comunidades sobre los derechos. Comprendo una duda que yo mismo mantengo. No es la solución ideal. Pero en las circunstancias descritas, pienso que era la menos mala. Y aún hubiese sido mejor si el Estado hubiese aprobado una posible norma marco y las Comunidades hubiesen desarrollado unos mínimos de coordinación al objeto de establecer unos parámetros comunes para esas leyes.

La tercera etapa se corresponde con el segundo estado de alarma. Como indiqué, en este caso el debate se deriva del presupuesto del Real Decreto.

${ }^{11}$ Así, Decreto-Ley 7/2020, de 19 de octubre de la Comunidad Autónoma de Aragón, por el que se establece el Régimen jurídico de alerta sanitaria para el control de la pandemia covid-19 en Aragón. 
¿Puede delegarse en las Comunidades Autónomas la capacidad de adoptar medidas que restrinjan incluso con severidad derechos y libertades? Si la mera delegación ofrecía dudas, un objeto como el analizado, las agrava. La mera vigencia del estado de alarma, en principio, debería restringir la capacidad de las Comunidades Autónomas al respecto. Si en relación con la fase de transición he planteado la posibilidad de que una ley autonómica pudiese servir de cobertura a este tipo de medidas era, precisamente, por la ausencia de un estado de alarma que facilitase medidas más ortodoxas. Declarada la alarma, parece que lo razonable es, al menos, regresar a la ortodoxia y dejar en manos del Estado la adopción de las medidas que restrinjan los derechos y libertades, como mínimo de aquellas que lo hagan con especial intensidad. Puede alegarse que es el Estado mediante el texto del Real Decreto el que establece esas limitaciones. Ello podría ser en el caso de que se aceptase la delegación como suficiente para una incidencia menor, para la modulación de derechos. No creo que lo sea cuando esa afección pueda llegar a la frontera con la suspensión. Por otro lado, como ya indiqué, la delegación es excesivamente amplia y de esta forma, contraria a los principios que rigen la interpretación de los derechos y libertades.

\section{LECTURAS PARA EL FUTURO}

Los fallos que se pueden relacionar con el modelo territorial no son inherentes a la descentralización. Ni, me atrevería a decir, al diseño constitucional. Están directamente relacionados con malas prácticas políticas y de gestión. Prácticas que desde hace tiempo están erosionando el conjunto de las instituciones estatales $^{12}$. Los problemas, que existen, del diseño constitucional no serían tan graves $y$, desde luego, en un momento de crisis no habrían tenido las consecuencias que se han visto. Así las cosas, es necesario detenerse. Detenerse y realizar un diagnóstico global de funcionamiento del Estado. De alguna manera, es preciso reconstruirlo.

Desde esta premisa general, y en primer lugar, se necesita un diagnostico concreto. Un diagnóstico sobre aquello que estos meses ha evidenciado que funciona mal. Un diagnóstico que deberá vincularse a una reflexión sobre cuál

12 Vid, J. Tudela Aranda, Crisis política (y social) y Derecho Constitucional, Teoría y Realidad Constitucional, no 46, pp. 173-210. 
es la asignación de competencias más correcta para la eficacia y mejor ejecución de las políticas públicas. Más allá de la dialéctica centralización /descentralización, es imperioso fijar la atención en la eficacia de las políticas públicas. Un criterio que debe ser determinante para la asignación de competencias y que obliga a no olvidar la posición de los entes locales en la organización del poder. En tercer lugar, hay que dejar de hablar de descoordinación y relaciones intergubernamentales para pasar a la acción. En el terreno político y en el terreno administrativo. $Y$ es importante que se haga tanto entre el Estado y las Comunidades Autónomas como entre estas. Así, comenzar trabajando desde los principios de realismo, estabilidad y responsabilidad sería un ejercicio razonable. En cuarto lugar, es preciso generalizar una política de la transparencia y de la responsabilidad. Los ciudadanos deben saber qué hace cada Administración y con qué medios. También hay que generalizar la asunción de responsabilidad por errores o, simplemente, mala gestión. La autonomía debe defenderse desde una gestión virtuosa. Hay que desdramatizar la responsabilidad. Los errores son normales, comunes a cualquier sistema político. Simplemente, se deben reconocer y rectificar y, en su caso, acompañarse de la correspondiente asunción de responsabilidades. En quinto lugar, las Comunidades Autónomas deben repensar su forma de ejercer la autonomía. Es preciso que se dé preferencia a la calidad de la gestión y a la ejecución de verdaderas políticas públicas acordes con sus características que a excesos retóricos muchas veces traducidos en legislación innecesaria. En relación con ello, hay que dar más importancia a la Administración. Objetivamente se puede decir que uno de los fracasos de la España democrática es el modelo burocrático administrativo. Y creo que especialmente las Comunidades Autónomas no han prestado a este tema la atención que merece. No hay Gobierno eficaz sin una Administración capaz. Los retos del buen gobierno son cada vez mayores y más complejos y, sin embargo, las administraciones son cada vez más débiles y deudores de viejos vicios. En sexto y último lugar, hay que mirar a las entidades locales e integrarlas en la reordenación global del modelo territorial. Pensar el modelo territorial sin integrar en el diseño a provincias y, especialmente, municipios, ha sido un vicio de origen. Un defecto que el tiempo ha agravado. En la sociedad contemporánea el rol de los municipios es cada vez más relevante. Una adecuada ordenación de las políticas públicas exige tomarlos en consideración para asignarles las correspondientes competencias. 
Por supuesto, se pueden pensar otras líneas de trabajo. Es más, las hay y es preciso desarrollarlas. Con las palabras que anteceden sólo he querido reflejar una aproximación a un programa de trabajo. Existe acuerdo, como se ha visto en estas mismas páginas, en que la reforma del modelo territorial es imprescindible. Un acuerdo que después de la pandemia aún tendrá apoyos más firmes. Es más, no es posible saber si el statu quo podrá permanecer impasible ante las exigencias de cambio derivadas de la misma. Con las propuestas planteadas y con otras similares que pueden formularse, sólo he querido poner de manifiesto que esa reforma es terrenal, que debe abordarse desde cuestiones concretas que escapan a las grandes definiciones del Estado. Es posible que algún día haya que visitar la metafísica. Pero los ciudadanos no pueden esperar hasta ese momento para tener un Estado más eficaz. Es preciso comenzar a trabajar ya en reformas concretas.

Una última idea. Nada será posible si no se modifican totalmente las pautas de comportamiento. En dos sentidos. Todos tienen que ser respetuosos con las exigencias del Estado de derecho y buena administración. $Y$ todos tienen que ser coherentes con las exigencias de la cultura federal. Por supuesto, en su momento ello puede exigir la reforma de la Constitución. Pero creo que sería un grave error depositar en la reforma de las normas jurídicas todas nuestras esperanzas. Sólo si cambia la cultura política y con ella el comportamiento de las élites, será posible intentar el éxito. Abandonar el sectarismo por la cultura del acuerdo. Recuperar el rigor y la capacidad como criterio de gestión. Asumir con naturalidad el respeto a las instituciones y al Estado de Derecho. Son sólo algunos de los sustentos de esa cultura. $Y$ todo ello, presupuesto de la reforma territorial. 